\title{
La protección del patrimonio arqueológico en Castilla-La Mancha. Reflexiones sobre la Ley 4/2013 de patrimonio cultural
}

\author{
La nueva Ley 4/2013 ha aportado al panorama arqueológico de Castilla-La Mancha importantes novedades \\ que el autor analiza y comenta desde una óptica personal. La Ley, aprobada la pasada primavera, \\ multiplica los instrumentos jurídicos con que se dota a la Administración competente en la conservación \\ del patrimonio cultural. Asimismo, supone el complemento normativo necesario al innovador Código \\ Deontológico de la Arqueología y Patrimonio de Castilla-La Mancha recientemente aprobado en esta \\ región. Este innovador Código aborda aquellos aspectos que, por implicar más a la ética que a la norma, \\ no son definidos por ésta.
}

Luis Benítez de Lugo Enrich | Dpto. de Arqueología y Prehistoria, Universidad Nacional de Educación a Distancia

URL de la contribución <www.iaph.es/revistaph/index.php/revistaph/article/view/3386>

\section{Introducción}

La regulación de la actividad arqueológica en CastillaLa Mancha se había venido rigiendo desde finales de la década de los ochenta hasta mayo de 2013 , en lo que a la normativa regional se refiere, principalmente por la Orden de 20 de febrero de 1989 para la regulación de las investigaciones arqueológicas y paleontológicas en Castilla-La Mancha y por la Ley 4/1990 de Patrimonio Histórico de Castilla-La Mancha.

La Orden de 1989, sucesora de una orden similar promulgada el año anterior, ha venido definiendo las condiciones para desarrollar intervenciones arqueológicas en Castilla-La Mancha los últimos veinticuatro años, lo cual ha sido una notable deficiencia en la gestión de la arqueología en la comunidad autónoma. En primer lugar porque no se promulgó con ese fin y también porque el panorama de la arqueología ha cambiado profundamente en España a lo largo de las últimas décadas, dejando obsoleta a esa Orden hace ya varios lustros. Cuando se redactó la Orden el panorama arqueológico era exclusivamente el de unas pocas excavaciones arqueológicas, programadas un año para excavar durante unos meses del verano siguiente. Hace ya décadas que la arqueología preventiva hizo su aparición en Castilla-La Mancha, siendo desarrollada con un marco jurídico claramente insuficiente, obsoleto e incumplido desde la propia Administración regional.
Al año siguiente de aparecer aquella longeva Orden fue promulgada la Ley $4 / 1990$, de 30 de mayo, del Patrimonio Histórico de Castilla-La Mancha. Esta ley fue un hito debido a que fue la primera en ser aprobada por una comunidad autónoma en el ejercicio de sus competencias sobre esta materia. Se aprobó antes, incluso, de esperar a una sentencia del Tribunal Constitucional que en 1991 modificó en cierta medida los niveles de competencias sobre el Patrimonio Histórico de las comunidades autónomas. Por ello puede considerarse que fue una ley precipitada, resultando además "la menos elaborada" de todas las que fueron surgiendo a partir de ese momento en las diferentes comunidades autónomas, destacando "la escasez de novedades" de este texto legal con respecto a la Ley 16/1985 de Patrimonio Histórico Español, de la cual en ocasiones llegó a ser una copia literal (QUEROL; MARTÍNEZ DÍAZ, 1996).

Esta ley nunca llegó a ser complementada, durante sus más de dos décadas de vigencia, con un desarrollo reglamentario; un reglamento que hubiera quizás servido para solventar las deficiencias de la ley, incrementadas con el paso de los años por el dinámico panorama del sector arqueológico.

En anteriores legislaturas los profesionales de CastillaLa Mancha asistimos, esperanzados, a varios conatos de redacción de una nueva ley de patrimonio o de un regla- 


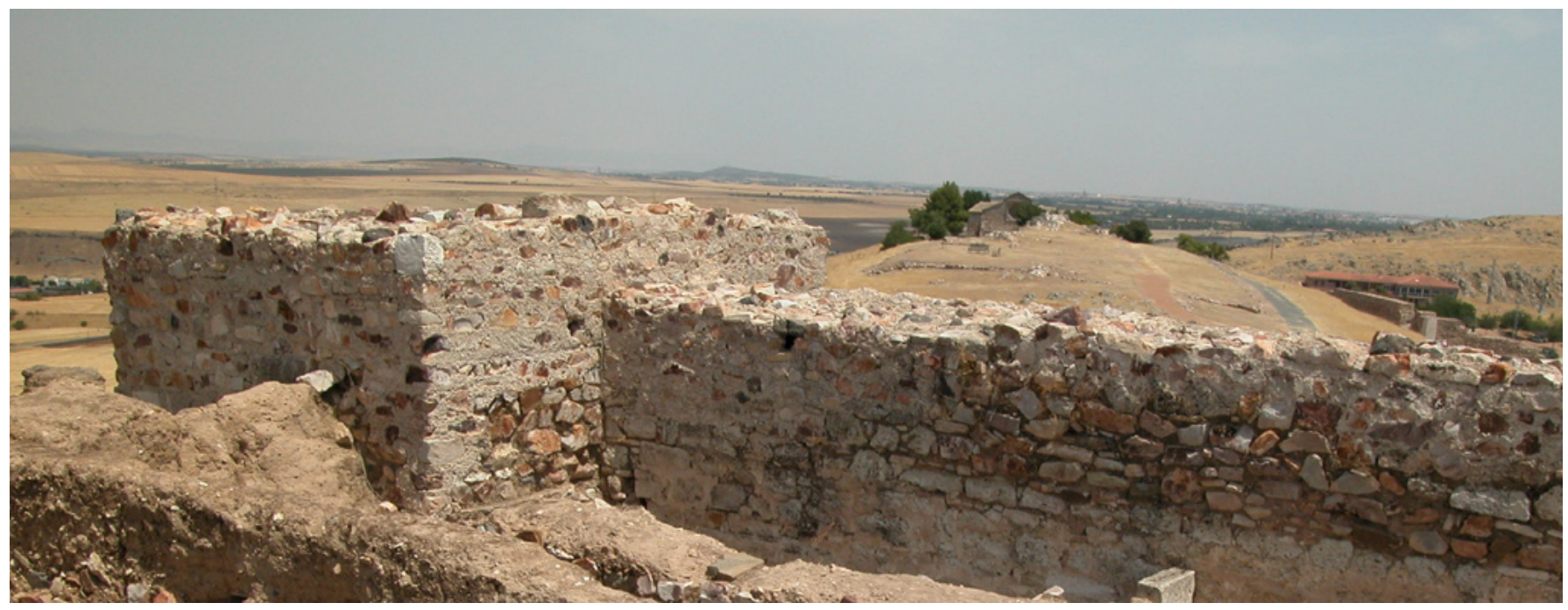

Reconstrucción en el Parque Arqueológico de Alarcos | foto Luis Benítez de Lugo Enrich

mento para la ley existente. Fueron todos intentos fallidos, que implicaron el pago de honorarios a gabinetes jurídicos externos o a expertos procedentes de universidades. Estas tentativas pusieron en evidencia la falta de conciencia e interés real del gobierno regional a la hora de dotar al patrimonio de unas herramientas jurídicas y administrativas modernas, comparables a aquellas de las que se habían aprobado en otras comunidades autónomas. La promulgación ahora de la Ley 4/2013 es la mejor prueba de que "querer es poder", como reza el refranero castellano.

La exposición de hechos presentados en las líneas precedentes permitirá al lector hacerse una idea del contexto y el clima en el que los profesionales del sector hemos recibido la aprobada Ley 4/2013 de patrimonio cultural de Castilla-La Mancha (Diario Oficial de CastillaLa Mancha n. ${ }^{\circ} 100$, de 24 de mayo de 2013).

Al ser el panorama jurídico de partida de pobreza y escasez, las aportaciones que la Ley $4 / 2013$, de 16 de mayo, de patrimonio cultural ha traído a Castilla-La Mancha resultan importantes. Sin ánimo de realizar una revisión completa del nuevo texto legal, que resultaría inviable por falta de espacio, a continuación expondremos y comentaremos de forma preliminar algunos de los aspectos más significativos en lo que a la arqueología se refiere.

\section{Figuras de protección}

Algo polémicas han sido las nuevas figuras de protección de los bienes arqueológicos integrados en el patrimonio cultural, que han sido modificadas con respecto a la situación anterior. Si a efectos prácticos la protección real se limitaba antes a dos tipos -los elementos inventariados en carta arqueológica y los bienes de interés cultural- ahora las categorías contempladas por la nueva ley son tres. Los bienes de interés cultural (BIC) son aquellos "singulares y sobresalientes", mientras que los bienes de interés patrimonial (BIP) son los simplemente "relevantes". Finalmente, los elementos de interés patrimonial (EIP) podrán ser aquellos que, sin ser dignos de alcanzar las categorías anteriores, sí cuentan con algún valor patrimonial. La subjetividad -y, por tanto, la indeseable indefinición- de estos conceptos recogidos por la norma es grande.

\section{Catálogo e Inventario del Patrimonio Cultural}

Otra novedad es la creación del Catálogo del Patrimonio Cultural de Castilla-La Mancha, en el cual se inscribirán los bienes de interés cultural, los de interés patrimonial y los elementos de interés patrimonial (BIC, BIP y EIP, respectivamente). El director general de Cultura ha explicado que para desarrollar el Catálogo se han previsto 55.000 euros: 7.000 euros en 2014, 30.000 euros en 2015 y 18.000 euros en 2016. En 2013 no hay posibilidad de aplicar presupuesto alguno a este proyecto. 
Este Catálogo, que incluirá a los elementos señeros del patrimonio castellano-manchego, no sustituye al Inventario del Patrimonio Cultural de Castilla-La Mancha (la antigua carta arqueológica), instrumento de gestión que aparece recogido en la nueva ley de forma perfeccionada.

Por fin esta ley ha dotado de base jurídica a las figuras de los ámbitos arqueológicos, que venían manejándose desde hace más de una década sin fundamento legal alguno. Según la nueva ley, los ámbitos de protección son aquellas áreas en las que está probada la existencia de elementos de valor patrimonial, mientras que los ámbitos de prevención son las zonas en las que sólo existe una presunción razonada de la existencia de esos bienes.

\section{Deber de conservación y permiso de acceso a bienes culturales}

Esta ley es mucho más exigente que la anterior con el deber de conservación de los propietarios o poseedores de los bienes arqueológicos. Ya no sólo estarán obligados a su mantenimiento en buenas condiciones, sino que se ha dotado a la Administración competente de herramientas jurídicas importantes para garantizar la conservación del patrimonio.

Los propietarios y poseedores del Patrimonio están obligados además a permitir el acceso a esos bienes en varios casos. En este punto cabe destacar la posibilidad que ahora tienen los investigadores autorizados por la Consejería para acceder legalmente a su objeto de estudio allá donde se encuentre, siempre y cuando en su autorización se expresen los límites de su acceso y de su ámbito de actuación.

\section{Reconstrucciones de inmuebles}

En otro orden de cosas, llama la atención que la Ley 4/2013, de 30 de mayo, del Patrimonio Histórico de Castilla-La Mancha, indique que se evitarán los intentos de reconstrucción en edificios de interés histórico, permitiéndose sólo aquellos indispensables para la estabilidad y el mantenimiento del inmueble. Aplicando este criterio el Parque Arqueológico de Alarcos (Ciudad Real) -por poner un ejemplo de proyecto emblemático liderado por la Administración regional- sería hoy otro (mucho menos atractivo, posiblemente).

\section{Funcionarios de la Consejería de Cultura, agentes de la autoridad}

Otra de las novedades de la Ley 4/2013 es la consideración de agentes de la autoridad a los funcionarios de la Consejería de Cultura, quienes han quedado habilitados para recabar información y documentación. Entre sus funciones se encuentran las de vigilancia e inspección, la de información y propuesta de medidas cautelares, correctivas y sancionadoras o el levantamiento de actas de inspección, que tendrán presunción de veracidad. Estos nuevos agentes de la autoridad estarán provistos de la correspondiente acreditación identificativa.

Sobre este asunto pueden realizarse tres consideraciones. La primera es que a los funcionarios de la Consejería se les ha dado de golpe mucho más poder del que tenían, aunque también más responsabilidad y trabajo. La nueva ley va a modificar sus condiciones laborales. En segundo lugar, cabría esperar que las exigencias de la nueva norma razonablemente llevaran pareja la incorporación de personal especializado en los diferentes campos del patrimonio, que en este momento brilla por su ausencia en la Consejería.

Por otra parte, señalar que no hubiera estado de más que la nueva ley contemplara consecuencias para eventuales casos de malas prácticas administrativas de los funcionarios en el ejercicio de su actividad inspectora, tanto por dejadez como por ausencias flagrantes de inspección, o en casos de inspecciones con resultados manifiestamente parciales o deficientes.

\section{Detectores de metales}

La existencia en Andalucía de una legislación administrativa restrictiva en lo que al uso de los detectores de metales se refiere, unido a la falta total de regulación administrativa en Castilla-La Mancha, había provocado en la región castellano-manchega un "efecto llamada" a furtivos andaluces, varios de los cuales han sido detenidos por la Guardia Civil en los últimos años, principalmente en las provincias del sur de la región. El caso es que algunos detectoristas han venido expoliando 


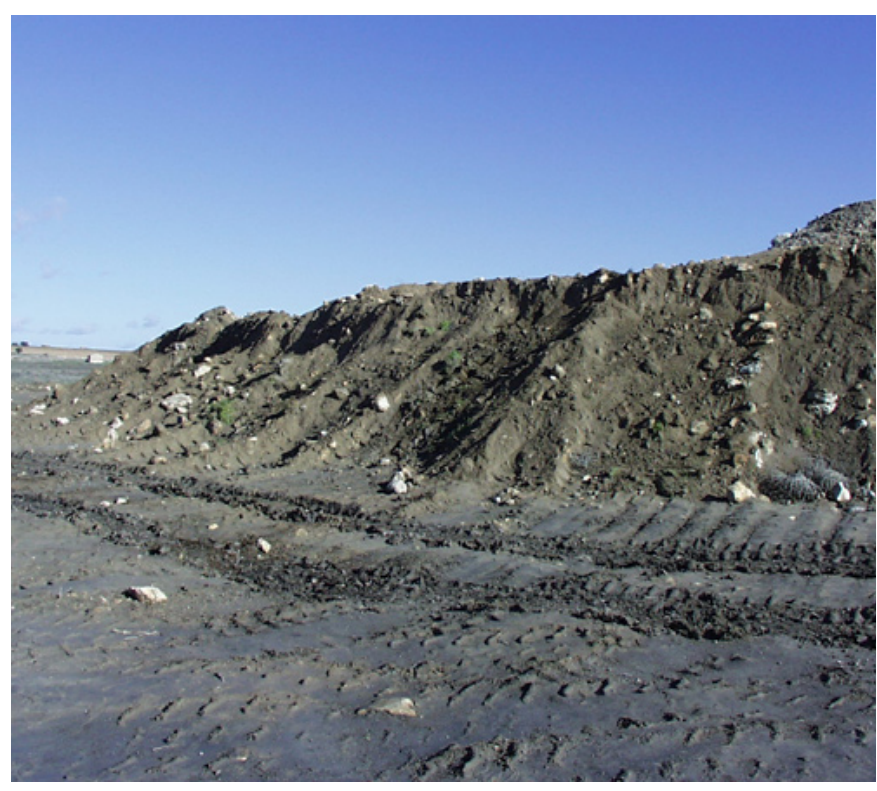

Motilla de la Máquina (Daimiel, Ciudad Real) tras la agresión de 2002. El dueño de la parcela quiso retirarla con maquinaria pesada y la Consejería de Cultura ni se personó en la causa penal abierta ni abrió expediente al responsable | foto Diego Clemente

durante estos años de atrás el patrimonio castellanomanchego sin grandes contratiempos, ni impedimentos legales procedentes de la normativa sectorial de patrimonio histórico.

A partir de mayo de 2013 esta situación ha cambiado drásticamente. El uso de un detector de metales en cualquier ámbito arqueológico de Castilla-La Mancha deberá ser autorizado por la Consejería con competencias en materia de Patrimonio; en caso contrario, se podrá sufrir una sanción de hasta un millón de euros en las infracciones muy graves.

\section{Conclusión}

La nueva Ley 4/2013 multiplica los instrumentos jurídicos con que se dota a la Administración competente en la conservación del Patrimonio Cultural, y supone el complemento normativo necesario al innovador Código Deontológico de la Arqueología y Patrimonio de Castilla-La Mancha recientemente aprobado en esta región (BENÍTEZ DE LUGO; GARCÍA-SOTO; LÓPEZ PRECIOSO, et ál., 2012). Este Código aborda aquellos aspectos que, por implicar más a la ética que a la norma, no son definidos por ésta.
Lo que está por ver es que la Administración regional cambie con esta nueva ley su conducta habitual de transigir con expolios y destrucciones, de los que hemos tenido escandalosos ejemplos en los últimos años.

En Castilla-La Mancha no ha habido prácticamente oposición social a la aprobación de la nueva ley de patrimonio, pues era una norma largamente esperada. El nivel de oposición a esta ley se encuentra lejos del rechazo suscitado por la vecina Ley 3/2013 de Patrimonio Histórico que el Gobierno de la Comunidad de Madrid ha aprobado el pasado mes de junio, con los votos en contra de todos los partidos de la oposición y con la crítica pública y unánime del Colegio Profesional de Arqueólogos de Madrid, de la Asociación Madrileña de Trabajadoras y Trabajadores de la Arqueología o la plataforma Madrid, Ciudadanía y Patrimonio, entre otros colectivos.

Aún siendo la castellano-manchega y la madrileña dos normas jurídicas creadas por el mismo partido político y en un momento similar el resultado es claramente diferente. Las críticas vertidas sobre el texto madrileño (desprotección del patrimonio, desmantelamiento de un modelo eficaz de gestión, etc.) no son extrapolables al caso castellano-manchego. La nueva norma de CastillaLa Mancha es un instrumento moderno, innovador y que supone una clara mejoría con respecto a la situación existente en legislaturas anteriores. Por ello hemos de felicitarnos y esperar que la nueva ley funcione como de ella se espera, aplicándose realmente a la protección, fomento y puesta en valor del patrimonio cultural de Castilla-La Mancha.

\section{BIBLIOGRAFÍA}

- BENÍTEZ DE LUGO, L.; GARCíA-SOTO, E.; LÓPEZ PRECIOSO, et ál. (2012) El Código Ético de la Arqueología y el Patrimonio en Castilla-La Mancha. Revista Jurídica de Castilla-La Mancha, 51, pp. 11-28

- QUEROL, M. ${ }^{a}$ A.; MARTíNEZ DÍAZ, B. (1996) La gestión del Patrimonio Arqueológico en España. Madrid: Alianza Universidad Textos, 1996, p. 130 